Instructions for authors, subscriptions and further details:

http://brac.hipatiapress.com

\title{
Dibuixar un arbre d'Àlex Nogué
}

\section{Rosa Pera Roca ${ }^{1}$}

1) Curadora Independent. Espanya

Date of publication: June $3^{\text {rd }}, 2014$

Edition period: February 2014-June 2014

To cite this article: Pera, R., (2014). Recensión del libro Dibuixar un arbre (Review of the book). Barcelona, Research, Art, Creation, 2(2), 248-251. doi: 10.4471/brac.2014.11

To link this article: http://dx.doi.org/10.447/brac.2014.11

\section{PLEASE SCROLL DOWN FOR ARTICLE}

The terms and conditions of use, except where otherwise noted, are related to the Open Journal System and to Creative Commons Attribution License (CCBY). The indication must be expressly stated when necessary. 
BRAC - Barcelona Research Art Creation. Vol. 2 No. 2, June 2014, pp. 248-251

\section{Reviews (I)}

\section{Dibuixar un arbre d'Àlex Nogué}

El text és un abstracte de la meva aportació a la presentació del llibre Dibuixar un arbre/Drawing a tree. Barcelona, 2013. Editorial Comanegra Català/anglès, 180 pàgines. Color ISBN: 978-84-15097-91-4 a la seu de l'editorial el 21 d'octubre de 2013. El llibre, liderat per l'artista Àlex Nogué, és una munió d'escrits en torn de la seva pràctica artística, amb reflexions fetes des de la filosofia, la docència, la creació, la poesia i l'anàlisi de l'art contemporani. Hi hem participat Eudald Camps, Xavier Franquesa, Angels Viladomiu, Victor Sunyol i jo mateixa.

He llegit el llibre de l'Àlex Nogué i he après coses noves i d'altres que no sabia que havia oblidat.

Conèixer no és el mateix que pensar: ho diu Jorge Wagensberg (2013), per qui coneixement és pensament simplificat, codificat i empaquetat, llest per sortir de la ment, atravessar la realitat i ensopegar-se amb una altra ment que el descodifiqui. Afegeix que existeixen tres mètodes i formes de coneixement: el científic, l'artístic i allò revelat.

Hi ha coses que hem vist repetidament, però que mai hem mirat amb atenció. De sobte, per un esllevisament de sentit, se'ns revelen com quelcom nou. Restaven ocultes, en algún lloc del pensament, en algun lloc del temps, o en ambdós alhora. Rescatar-les és un repte, a cops un plaer, de vegades dolorós. Si hem de triar un símbol de l'impertèrrit, és l'arbre; càpsula de temps viva, n'atresora invisible el registre. Decidir dibuixar un arbre a escala real és desafiar el temps.

Marcel Proust, el gran mestre de l'ocultament disseccionat per Maurice 


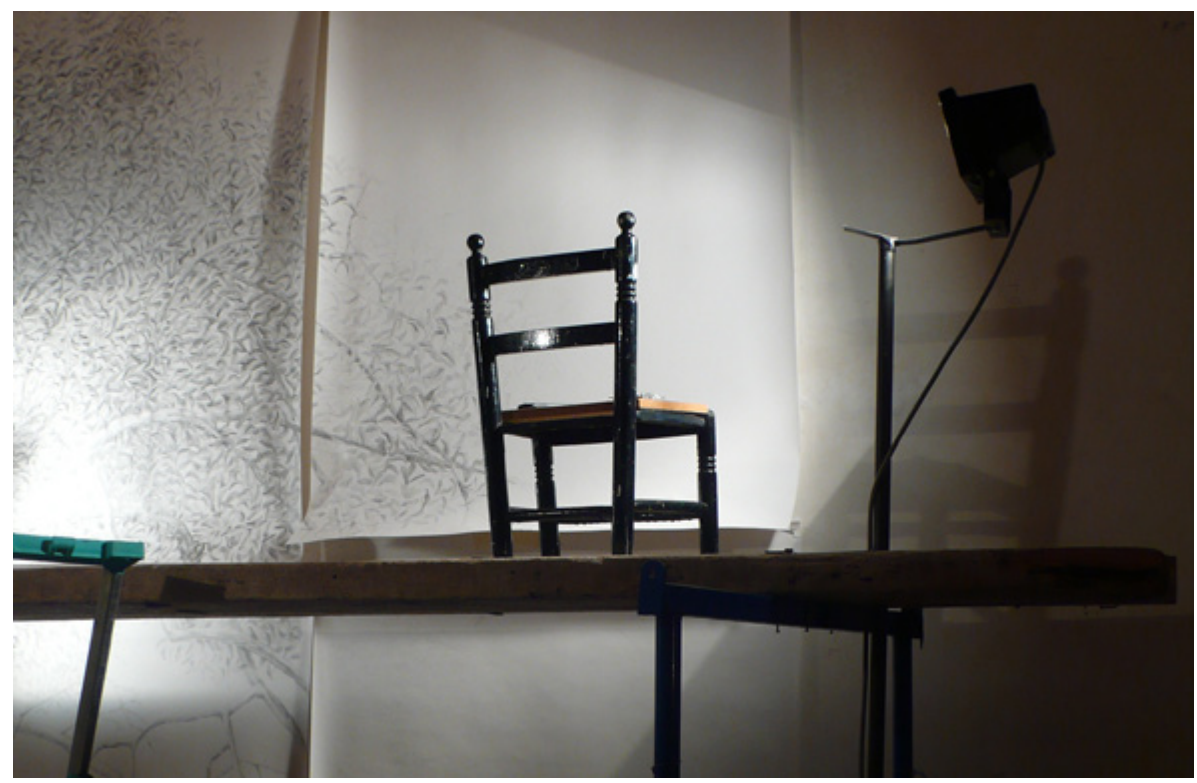

Figure 1. Dibuixar un arbre. Àlex Nogué. Imatge de l'autor. (C)

Blanchot (1995), és navegant avesat a entretelar irrealitat $i$ vida real en accedir a allò fabulós a través dels avatars quotidians. Ho fa mitjançant "una complicació potser enganyosa, però meravellosa" de totes les formes de temps. Així, "el temps destructor" o el "temps esborrat pel temps mateix" que paradoxalment dóna pas a experimentar "una mica de temps en estat pur" per "viure l'abolició del temps": "l'èxtasi del temps". El temps com espai buit, lliure. Temps pur: el temps en l'espai imaginari, el de l'art.

Experimentar. "Entrar en un dibuix és com entrar dins d'un núvol. Vistos de lluny els núvols tenen un contorn definit. Viscuts de prop experimentem que no tenen perfil i que no hi ha cap lloc concret que ens indiqui el moment de pas de 1'exterior a l'interior" (Nogué, 2013). "És una línia difusa”, explica Nogué, “com les imatges dels límits en les pel·lícules d'Angelopoulos. És de manera progressiva com les formes es fan difuses i en perdem la visió nítida. Una situació que té menys a veure amb un estat d'ànim indecís i més a veure amb un estat d'ànim complex". No puc més que recordar aquella "complicació enganyosa" que adivina Blanchot a l'escriptura que arrossega a espais ocults d'emoció i estranyesa de Proust. I penso que l'Àlex Nogué ha estat tocat per "l'èxtasi del temps" i que per això els seus dibuixos d'arbres grans i magnífics, 
250 Rosa Pera-Dibuixar un arbre d'Àlex Nogué

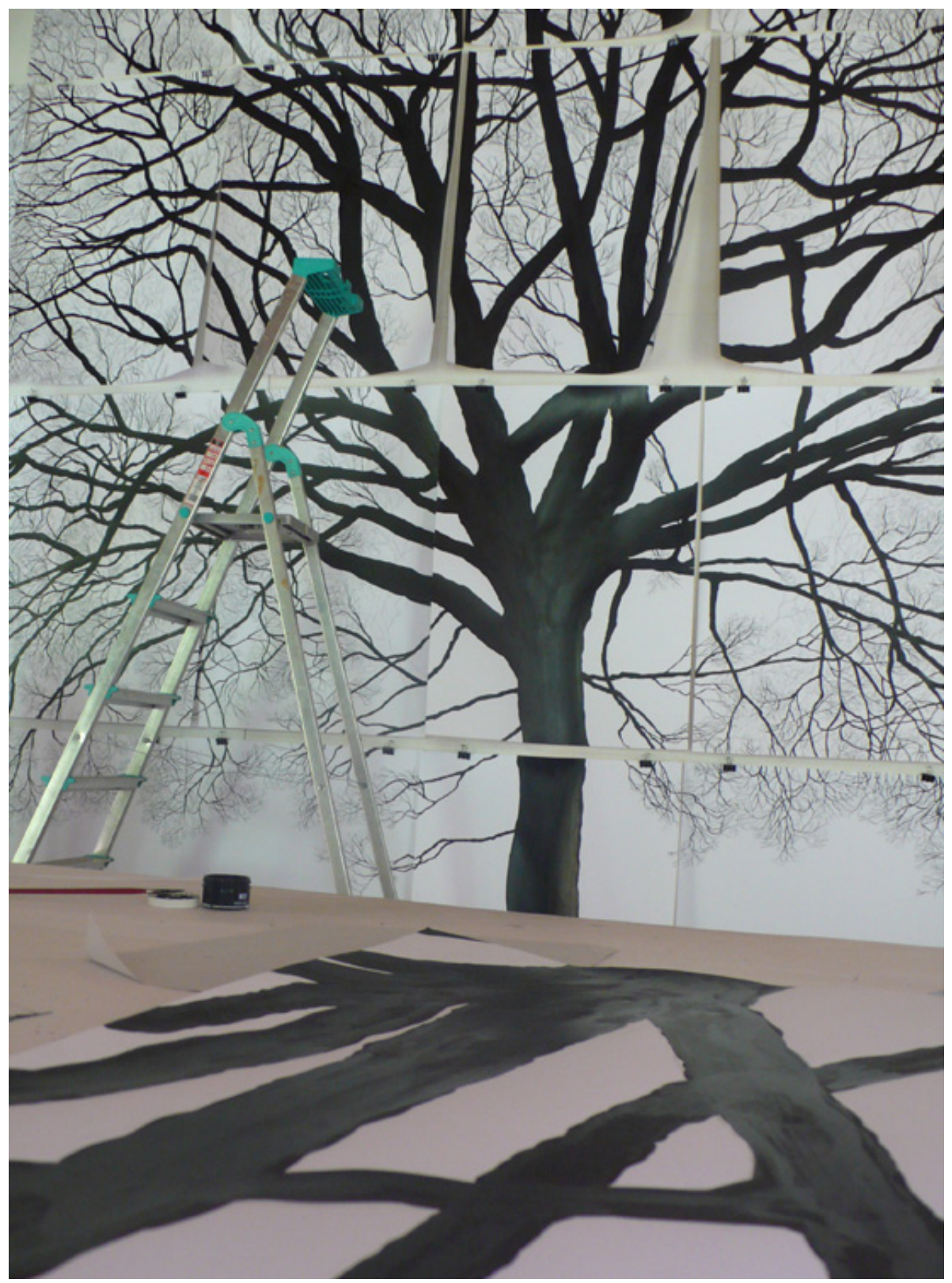

Figure 2. Dibuixar un arbre. Àlex Nogué. Imatge de l'autor. (C) 
delicats i torbadors alhora, poden atraure i engoixar a parts iguals en un instant de coneixement. És el temps de l'art.

Sabut és que l'art no consisteix en un mer mirar l'objecte per representar-lo. És quelcom més complicat. On rau, però, la complexitat? Potser dibuixar un arbre sigui una de les maneres possibles d'anar al moll de l'òs. Al núvol de Nogué s'amaga l'esfera densa de l'aprenentatge que retorna imatges i desitjos, en un diàleg intens i no sempre plàcid entre ment, ma, emoció, l'objecte (l'arbre) i qui llegeix el dibuix.

El dibuix com a temps perdut imprescindible per assolir el temps recobrat, en línies de temps que com diu Deleuze (1970), són "veritables línies d'aprenentatge".

Oportuna, l'evocació del preludi de L'eternitat $i$ un dia (Mia aioniotita kai mia mera. Théo Angelopoulos, 1998): "Diu el meu avi que el temps és un nen que juga a les bales". L'infant que aprèn perdent el temps, inadvertidament, cercant la posició òptima per esbossar les línies d'impacte perfectes. Un instant privilegiat que rememora el protagonista, precisament un escriptor, en boca del seu avi, quan ell mateix és ja un home madur, i en els darrers dies de vida vol transmetre coneixement al nen de futur incert i perillós que l'escolta, com ell, atemorit per l'esdevenir.

Prendre posició, a cada moment i a consciència: la millor brújola per circular pels camins de l'aprenentatge, de la vida. Amb l'experiència de la pràctica de l'art, no fos cas ens n'oblidéssim.

Rosa Pera. Curadora i investigadora d'art i cultura contemporànies rosapera@gmail.com

\section{References}

Blanchot, M. (1995). El libro por venir. Madrid: Ed. Trotta, 31-32.

Deleuze, G. (1970). Proust y los signos. Barcelona: Anagrama, 35.

Nogué, Àlex. (2013) Dibuixar un arbre / Drawing a tree. Barcelona: Ed. Comanegra, 86.

Wagensberg, J. (2013). El mapa del conocimiento. La Maleta de Porbou $n^{o}$ 1, p. 12. 